\title{
SHARING A PRAGMATIC NETWORKED MODEL FOR OPEN PEDAGOGY: THE OPEN HUB MODEL OF KNOWLEDGE GENERATION IN HIGHER- EDUCATION ENVIRONMENTS
}

\section{Lee Graham 1 \& Verena Roberts 2,*}

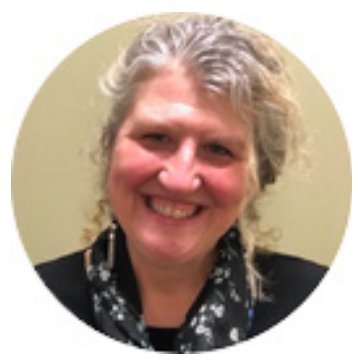

1 Lee Graham. State University College of New York at Oneonta, Oneonta, New York 13820

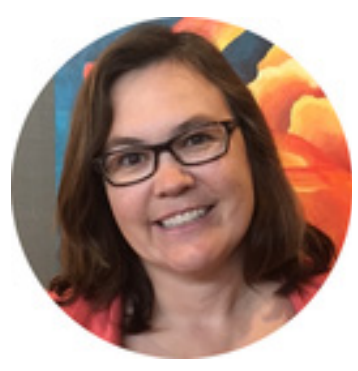

2 Verena Roberts. Werklund School of Education, University of Calgary, Calgary, Alberta, Canada

*Address all correspondence to: Verena Roberts, Werklund School of Education, University of Calgary, Calgary, Alberta, Canada; Tel.: (+1) 403239 7090; E-mail: verena.roberts@ucalgary.ca

\section{Abstract}

We outline a model for innovative online practice called the open hub model of knowledge generation in higher-education environments. Following from models such as communities of inquiry, communities of practice, and learning in the collective, we present a model that is based on a modified connectivist practice to support teachers in creating learning environments in which they can develop and expand tools for learning in an age of rapid change and information abundance. We explore literature on designing for an open pedagogical environment, specifically in terms of the usefulness of a blog for realization in 
these contexts. We also consider stages of open-learner readiness. The open hub model uses aspects of other models, designs, and stages to create a flexible method to initiate and develop open learning and practice for inservice teachers, preservice teachers, and faculty so that they may organize, facilitate, and learn in such environments. We discuss implications for university policy, student learning, and digital literacies.

KEY WORDS: open pedagogy, open-educational practices (OEPs), formal learning, informal learning, generative curriculum, online learning, distributed learning, personal learning networks, personal learning environments

\section{INTRODUCTION}

Teachers today are expected to prepare students for ubiquitous learning in a networked world (Gros and Maina, 2016). Online and blended learning environments afford educators the opportunity to extend learning environments beyond the four walls of the traditional classroom, but pedagogical innovation has not been able to keep pace with technological change. Preservice and inservice teachers have the ability to learn about content as a result of access to the internet in multiple media, times, and methods, thereby influencing their kindergarten-12th grade $(\mathrm{K}-12)$ learners through intentional learning design. $\mathrm{K}-12$ learners must know how to find credible content, develop skills and competencies to think critically about content, and communicate their ideas by connecting and collaborating with others, outside the classroom. These types of participatory learning activities are facilitated by open learning as a result of teacher-designed open-educational practices (OEPs). In this article, we examine how blogging and social media integration can be used to design OEPs based on higher-education and K-12 teaching experiences during the last six years. We begin with an overview of current literature connecting changes in teacher-education programs to design for emerging learning environments. Next, connections between blogging and OEPs are described as emergent opportunities in online learning. Finally, we introduce the open hub model as a pedagogical open-learning model as a design for educators.

\section{REVIEW OF THE LITERATURE}

\subsection{Evolving Models for Teacher Education}

Anderson (2018) describes the historical transition of pedagogical practice and teacher training in North America as one that has been focused on craft knowledge and the science of teaching. Anderson suggests that in this time of information abundance, it would be useful for teachers to develop their professional teaching identity through authentic education programs, and the most effective of these programs model engaging 
learning opportunities that focus on how to teach, not what to teach, thereby emphasizing pedagogy over content (Anderson, 2018).

Historically, learning environments have been focused on teaching content knowledge, rather than pedagogy and adaptation of teachers as learners in dynamic technologymediated and -negotiated environments (Thomas and Brown, 2011). Shulman's (1986) pedagogical content knowledge $(\mathrm{PCK})$ is often cited as a more recent bridge between focus on content and focus on pedagogy. The technological/PCK (TPACK) model (Mishra and Koehler, 2008) provides new opportunities for learners by extending learning using technological tools. These models, however, predate or disregard information abundance that is created by the ubiquitous internet and knowledge negotiation and formation by both student and teacher. "If the history of educational technology teaches researchers anything then it is this: what begins as fresh, innovative and edgy quickly evolves to tired, redundant and banal" (Brabazon, 2012). In a time of rapid obsolescence (Powell and Snelling, 2004), new skills are needed so that teachers and students can remain relevant and up to date on pedagogical opportunities offered with the use of new technologies.

Garrison et al.'s (2000) exploration of communities of inquiry identifies how social, teaching, and cognitive presence correlate directly with student satisfaction and perceived learning in online learning environments (Richardson et al., 2017). Cognitive presence is important for content delivery and understanding. Teaching presence focuses on the application of pedagogical strategies for learning during class. Social presence is vital to modeling learning processes through interaction, connection, and communication.

Wenger and Lave (1998) have taken a different approach with their communities of practice model. Within this model, in face-to-face or online environments, individuals enhance their knowledge by moving from a position of apprenticeship and nonparticipation in a learning community to a more fluid stance of participant as observer, reviewer, critic, and/or content producer. According to Downes (2005), "In the world of e-learning, the closest thing to a social network is a community of practice, articulated and promoted by people such as Wenger in the 1990s." Although these communities may exist in formal or informal environments, in person or online, the model provides an opportunity to take advantage of social learning to scaffold individual growth.

Thomas and Brown (2011) introduce the observation of learning in the collective in today's technological space. According to these authors, individuals learn with an aim to belong to the collective. The participant's contributions to the collective define his/her membership. Teacher and student roles fade in collectives, and instead, all members act as both teacher and student. When knowledge is so available and students are permitted to take an active role in creating course materials, the teacher may take the role of mentor and thereby provide structure and encouragement for students. The teacher no longer 
"delivers" information to students but, instead, guides and models, along with other members of the collective, the creation of quality interactions meant to bridge the gap between ubiquitous information and potentially outdated information. Although Thomas and Brown caution against structure and required contributions within a collective, adaptations of this model may be applied to formal educational environments, as demonstrated by Jones and Graham (2015).

\subsection{Models for Open Learning in Formal or Informal Environments}

Each of these models examine and may be applied to formal online learning communities, whereas connectivism considers how learners can connect and build organic personal learning networks to extend beyond digital classroom walls. According to Siemens (2004), connectivism is based on the following principles:

1. Learning and knowledge rest in diversity of opinions.

2. Learning is a process of connecting specialized nodes or information sources.

3. Learning may reside in nonhuman appliances.

4. Capacity to know more is more critical than what is currently known.

5. Nurturing and maintaining connections is needed to facilitate continual learning.

6. Ability to see connections among fields, ideas, and concepts is a core skill.

7. Currency (accurate, up-to-date knowledge) is the intent of all connectivist learning activities.

8. Decision making is itself a learning process. Choosing what to learn and the meaning of incoming information is seen through the lens of a shifting reality. Although there may be a correct answer now, it may be wrong tomorrow due to alterations in the information climate affecting the decision (Siemens, 2004).

Early connectivist environments focused on blogging and Twitter as hubs for learning experiences (Joksimov et al., 2015). Blogs can be an important component to collaborate, connect, and expand one's learning in today's online environments. In describing principles of rhizomatic learning (a model of informal learning), Cormier (2014) indicates that "...curriculum is not driven by predefined inputs from experts; it is constructed and negotiated in real time by the contributions of those engaged in the learning process." This open information generation with the community as the curriculum is the desired outcome of our open-education pedagogy. However, this knowledge construction and trust may not occur without working through technological and pedagogical readiness with participants in the learning experience. 
The concept of experiencing education by connecting with community in relevant ways is not new; however, according to Howard (2014) these practices do not regularly occur in current learning environments and are still in their infancy. Dewey (2008) is well known as an advocate for connection between learning inside and outside the formal classroom to provide learners with authentic experiential learning experiences. The opportunity for teachers to connect with learners outside the classroom provides a means to bridge both perceived and real historical pedagogical boundaries.

\subsection{Designing for an Open Pedagogical Environment}

As teachers, we do not know the stories and narratives that our learners bring to our learning spaces. As such, it is essential to promote and consider multiple voices and perspectives from the beginning of a course, especially in online learning environments. Design principles that emphasize diversity of perspectives can be of value in building or facilitating learning spaces and include the following spatial components in which learners:

1. Control the space

2. "Hang out" and "muck around"

3. Learn

4. Grow into new roles and responsibilities

5. Practice oral and written language

6. Express self and cultural identity through multimodal forms

7. Develop and engage in enterprise

8. Engage with the world (Kral and Schwab, 2012).

These design principles set clear expectations about guidelines and expectations in safe online learning spaces. It is up to students to maintain these safe online spaces as they develop their own personal learning networks.

As we begin open practice, the most important aspect to consider is the level at which students are comfortable in the open. Stages of openness have been considered in research and practical contexts. Cronin (2017) examined the relationship between openness and praxis in university educators by identifying four levels of OEPs that determine the extent and manner of OEP praxis:

Macro: Global level (will I share openly?)

Meso: Community/network level (who will I share with?) 
Micro: Individual level (who will I share as?)

Nano: Interaction level (will I share this?)

Teachers as professional learners have also considered learning openly in stages. Lucier (2017) wrote about "seven degrees of connectedness" that follow similar levels as Cronin's (2017) levels of OEP. Levels include (1) lurker, (2) novice, (3) insider, (4) colleague, (5) collaborator, (6) friend, and (7) confidant. Designing for openness includes scaffolding for open-learning opportunities, during which every learner feels comfortable. Graham and Fredenberg (2015) outline four stages of readiness in online open practice: resistance, awareness, emerging, and master. They suggested in their pilot study on connectivist behaviors of online teachers that "The ability to locate, read and make meaning from the blogs, as well as contribute to the blogs of others was a high indicator of both master and emerging practice in connectivism. These teachers indicated that they valued their experience and felt that it was one they wished to share with their own classroom students." Conversely, those who presented at a level of resistance had a negative experience with the open-learning setting for knowledge construction, and those who presented at a level of awareness saw benefits in their bounded open environment, but only in terms of content delivered by the teacher, without regard to the artifacts created by themselves or other students.

Designing for an open pedagogical environment requires policies, institutional or classroom based, to protect personal data and digital identity. Students in formal learning environments receive grades and achievement-related feedback that must be secure to comply with student privacy laws. Current legislation for each geographic area [e.g., Family Educational Rights and Privacy Act (FERPA), Freedom of Information and Protection of Privacy Act (FOIP)] must be considered, placed in writing, and described to all students. An institution's acceptable use of technology policy must also be examined. Most importantly, all students must be given a choices and options in terms of how they can participate in class activities. Blogging provides an opportunity for instructors and learners to consider open learning based on their own personal comfort level, competencies, and values while continuing to supporting others with different comfort levels, competencies, and values.

\subsection{Blogging as an Application for Open Practice}

OEPs provide a pedagogical framework in which to consider blogging as the center of an open experience. Cronin (2017) defines OEPs as collaborative, and they include creation, use, and reuse of open educational resources (OERs), as well as pedagogical practices using participatory technologies and social networks for interaction, peer learning, knowledge creation, and learner empowerment. Building on Cronin's (2017) definition, 
OEPs in $\mathrm{K}-12$ contexts describe an intentional design that expands learning opportunities for all learners beyond classroom walls and across cultures through collaboration, knowledge sharing, and networked participation (Roberts, 2018a).

Hodgkinson-Williams and Gray (2009) describe open pedagogy as "the opening up of educational processes...enabled by Web 2.0 technologies," and they suggest that open pedagogical approaches will be more transformational to learning contexts than open content. Alternatively, Wiley and Hilton (2018) describe a specific content-focused open pedagogical definition called OER-enabled pedagogy, "the set of teaching and learning practices that are only possible or practical in the context of the $5 R$ permissions which are characteristic of OER." The 5Rs (Retain, Reuse, Revise, Remix and Redistribute) refer to how open educational resources are used and contained as openly licensed content or public domain content.

These definitions stem from digital perspectives of open pedagogy that, according to Hegarty (2015), include the expansion of learning opportunities as a result of the following attributes:

1. Participatory technologies

2. People, openness, and trust

3. Innovation and creativity

4. Sharing of ideas and resources

5. Connected community

6. Learning generated

7. Reflective practice

8. Peer review

OEPs can be described in multiple ways; but we believe that the ways in which attributes of open pedagogy and access to safe learning spaces, through interactions with others can be integrated and modeled into teacher learning contexts have the potential to shape and transform education. Blogging provides a learning environment that can integrate content knowledge and pedagogical choice and serve to extend and connect other learners and cultures; it provides an extension of TPACK by including learner voice and choice. Indeed, blogging may embody the connections between human beings as a major component in the learning process.

Figure 1 illustrates Roberts' (2018b) open learning design intervention (OLDI) model. OLDI provides strategies to support the stages that a teacher experiences when considering 
OEPs and uses student blogs and an open hub blog that is described later in this article. According to Fig. 1, the first stage of OLDI is development of relationships between teachers and students. The second is development of student and teacher digital literacies. The third supports intentional interactions, collaboration, and connections with other nodes of learning that can include other people, content, social media, networks, and online communities. The fourth stage is development of a personal learning network that promotes student control to customize their learning objectives, content, method, and pace (Drexler, 2014) to connect with others (Downes, 2012). In addition, students have a choice about whom they connect with, how they connect with others, and how they describe their learning in their own way (Wilson et al., 2006). Students use personal blogs throughout the OLDI model, and teachers use a central blog as an open hub with which students can choose to connect, interact, and build their personal learning environments.

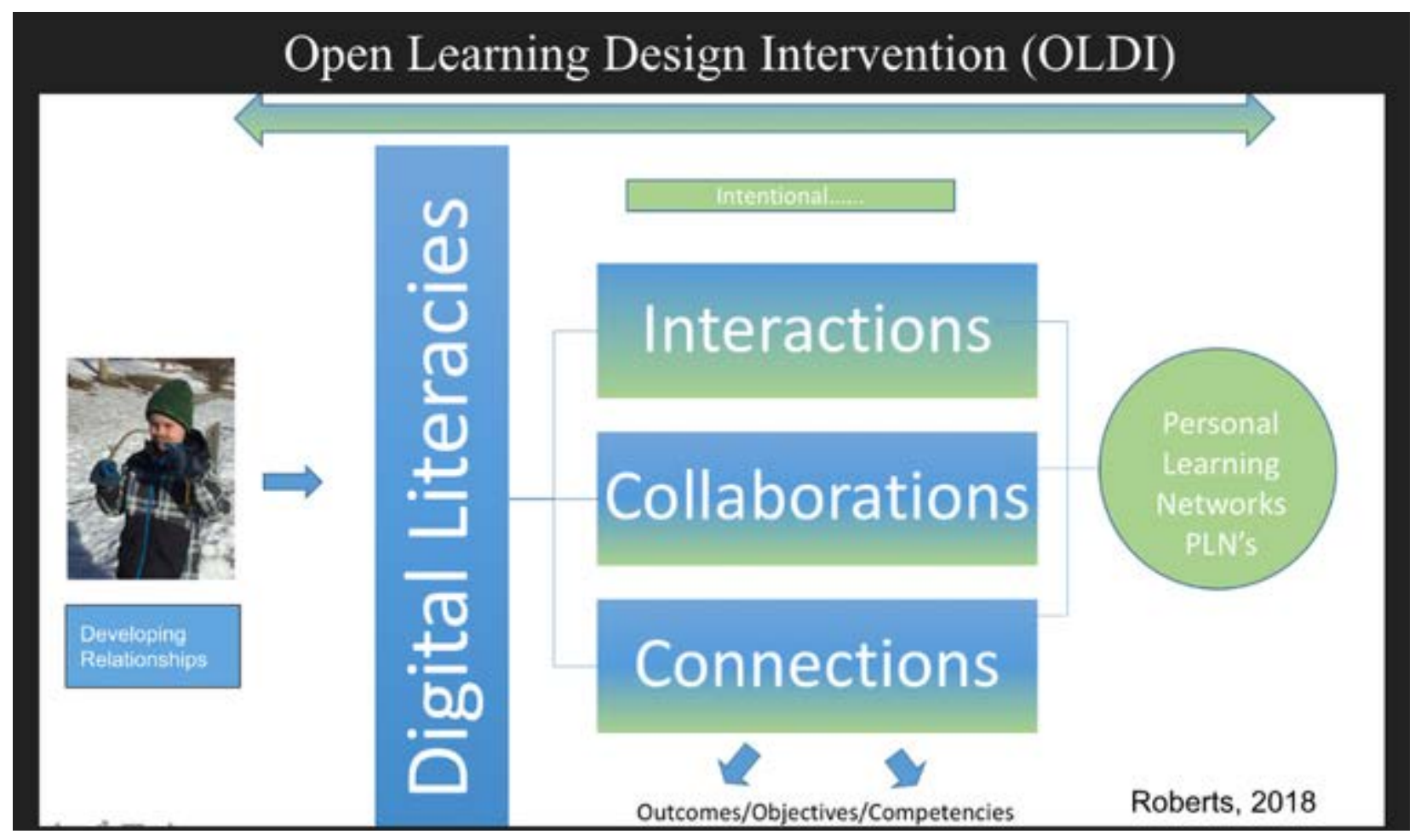

FIG. 1: OLDI model (Roberts, 2018b). PLNs, Personal learning networks

An open course blog can connect formal learning communities to informal learning networks, providing an expanded knowledge base and audience for interactions and communication. In Cronin's recent research, she describes how instructors demonstrated OEPs: "Teaching openly took different forms; for example, inviting students to engage in discussion via Twitter, creating courses in WordPress blogs, and encouraging students to share their work openly" (2017). In addition, O’Donnell (2006) argues that "we need to look at blogging, not as an isolated phenomenon, but as part of a broad palette of cybercultural 
practices, which provide us with both new ways of doing and new ways of thinking." Downes (2005) also considers how blogging promotes emerging learning opportunities in e-learning.

What happens when online learning ceases to be a medium and becomes more of a platform? What happens when online learning software ceases to be a type of contentconsumption tool, where learning is "delivered," and becomes more of a content-authoring tool, where learning is created? The model of e-learning as being a type of content, produced by publishers, organized and structured into courses, and consumed by students, is turned on its head. Insofar as there is content, it is used rather than read-and is, in any case, more likely to be produced by students than courseware authors. And insofar as there is structure, it is more likely to resemble a language or a conversation rather than a book or manual.

The e-learning application, therefore, begins to very much resemble a blogging tool, representing one node in a web of content, connected to other nodes and content creation services used by other students. It becomes not an institutional or corporate application, but a personal learning center, where content is reused and remixed according to a student's own needs and interests. It becomes, indeed, not a single application, but a collection of interoperating applications-an environment rather than a system.

As Dewey (2008) suggested in the early 20th century, education provides the opportunity for learners to expand their individual learning environments by connecting with others from different perspectives and cultures. Using an open course blog as a framework allows higher-education professionals to model and participate in the learning process as preservice and inservice teachers develop community and benefit from multiple perspectives as they learn in new ways, together, and online.

\section{NETWORKED LEARNING AS A STRATEGY FOR TEACHER TRAINING: THE OPEN HUB MODEL}

\subsection{Background}

During the past six years as colearners and learning partners with students, we have experimented with open learning by expanding learning opportunities using OEPs. We share here the model that has been most successful in our classroom use and outcomes of this model that are specific to open blogging. In addition, we suggest several options in emerging practice to adopt open learning with students.

As we considered how to create safe, scaffolded learning opportunities for educators and integrate digital literacies and emerging connected learning theory, we noticed a model developing throughout our online courses. Our open hub model identifies a clearly 
organized and scaffolded connection through progressively sophisticated and networked technology tools, allowing educators to generate content and develop their pedagogy and negotiated identity in a networked environment. The open hub acts as a familiar and safe portal for learners to "anchor" as they branch out and explore other communities and media. The active and participatory nature of the open hub depends on the individual student. The open hub serves as an organization point for the class that allows students to understand their challenge for content generation and organizes activity so that students, who may venture far into networked environments or stay close in the blog configuration, can organize their generated knowledge regardless of the tools used to create that knowledge.

We envisioned the open hub to be a beehive; a familiar community for centering, metacognition, and potential traditional-type online learning, if that is what is desired. It is the student's choice whether they wish to leave the hive and identify new and informal communities to impact their ongoing professional learning. Learner choice and flexibility are key: All learners, when ready, are provided with opportunities in terms of digital literacy competency, pedagogical mindset, and relationship (trust). The open hub is designed for openness based on these components.

\subsection{Preconditions for Using the Open Hub in Formal Learning}

Before asking students to use open learning through a blog, we examine our assumptions about the students who will engage. Do we assume that they are already well versed in social media use? If so, do we assume that this social media use is for a proactive and academic purpose? It is possible that the only way to make this determination is to ask. The Residents and Visitors map (White and LeCornu, 2017) provides educators a highly visual tool to determine the extent to which students use social media tools for workrelated or productivity purposes. However, the student who uses social media in this way is likely an outlier. In our experience, it is unlikely that preservice and inservice teachers (even long-time professionals in the classroom) have delved into social media use for productivity or professional assistance.

When this is the case, we are responsible for scaffolding students to prepare them to think about social media in a new way. As such, a candid conversation about digital literacies and a student's prior knowledge and ability in terms of digital literacies is an essential precondition. Learners at all levels benefit from a digital literacies toolkit that provides links on using technological tools and information about digital safety, privacy, and data and methods for searching and communicating online.

Requiring students to analyze blogs such as the \#DS106, Walk My World Project, Teaching with Social Justice in Mind Blog, and EquityUnbound can help students to see 
how educators use blogs and the professional purposes that they might serve. These blogs have been used to facilitate formal and informal open courses. This might lead to a conversation about why blogging is important in educational environments, privacy in online environments, and what students may interpret as positive or negative in these environments.

Although many students use social media as a social or entertainment tool, it is highly possible that they do not follow professionals in their field or connect with others for productive purposes. In fact, they may not be aware that social media is used for these purposes. Identifying thought leaders in social media and asking students to follow and observe these leaders is helpful for students as they consider working in the open.

Finally, as a part of the prework it is important that educators situate themselves as colearners in the experience. No one knows everything there is to know about responsible social media use, resources available, and the many tools that may be used to promote thoughtful and informed sharing on the internet. Acknowledging this to students at the onset creates conditions for a colearning environment in which all may be scaffolded, including the instructor of the class, so that growth may occur. Honesty is important in a time of information abundance and rapid obsolescence. One aspect of open learning with social media tools includes a willingness to be informed of something that we may not already know and to integrate this in an agile way into our pedagogical toolbox. If students interpret a new social media tool as valuable, including that tool in the conversation will only add additional paths to openness in the classroom experience. Not all students benefit from these paths, but some may.

Very few students and professors (regardless of age) are ready to be entirely open about their learning experiences immediately (Cronin, 2017). Prework helps us determine the extent of technical realities that are already in place in a student's world and assists in laying a foundation for the work that presents the community as the curriculum (Cormier, 2014). Even so, once we are faced with the reality of open practice, additional scaffolding is usually necessary.

\subsection{Open Hub Model of Knowledge Generation in Higher Education}

The open hub model of knowledge generation in higher education (see Fig. 2) (Graham, 2018) allows flexibility in student choice and integration of its principles into formal online learning experiences. Such familiarity integrates multiple networks to make the most of knowledge generation in multimodal contexts for the purposes of meeting specific objectives of a class. The model in Fig. 2 is color coded to indicate stages of openness that might be used in sequence as students develop their technological skills and comfort with knowledge generation in the open. It is helpful to those who have enrolled in a formal 
learning environment with no expectation of open practice to engage in an asynchronous online class, through which they can learn self-regulation and expression through technology (Graham and Fredenberg, 2015).

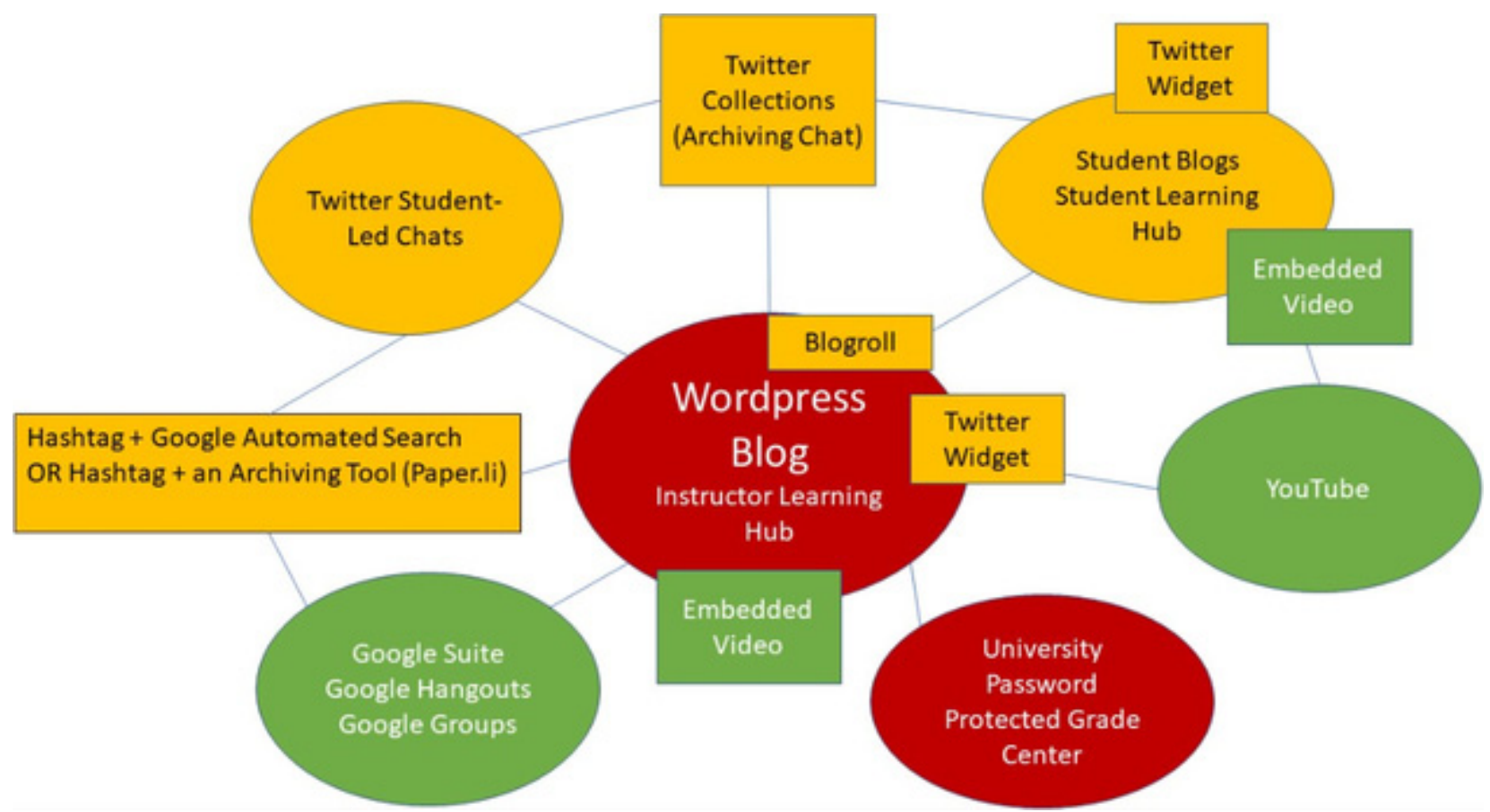

FIG. 2: Open hub model of knowledge generation in higher education, based on Graham (2018)

The first stage of open practice in a formal higher-education environment (colored in red in Fig. 2) includes a classroom blog linked to a secure area for grades and feedback. During the second level of open practice in a formal higher-education environment (colored in yellow), students create their own classroom blogs and lead scheduled Twitter chats based on objective-oriented essential questions (Wiggins and McTighe, 2005). Students also work with hashtags to organize contributions to the classroom community and archive knowledge generated within the classroom community. In the third level of open practice in a formal higher-education environment (colored in green), students move from a textbased environment to multimodal self-selected open environments such as YouTube to generate learning objects and synthesize their work in the class. In this level of open online practice, student blogs become a functioning hub of their own, a dynamic representation of their experiences aligned with standards and tools that students find useful. 


\subsection{Scaffolding the Beginner}

Although informal open-learning environments are not graded, the higher-education experience is. We combine formal and informal methodologies, but standards and objectives must ultimately be measured, recorded, and used to determine concept mastery. In this beginning stage of open-education practice, students are participants in a classroom blog, choose the manner in which they identify themselves within the blog, and take part in activities much like those that would occur in Blackboard with a class blog or discussion board. These activities document student learning throughout the experience and can serve as a small step into the open that allows students to understand what it means to be in open practice and how they can choose to position themselves as they generate knowledge.

This blog, which is set up by the educator as the blog administrator and then populated by the students as authors within the blog, can be very useful for those who are new to transparent learning environments. The educator customizes the blog and, if necessary, creates categories for students. For instance, in a large class the educator may create group categories so that students can focus only on posts made by their own group as the members respond to others. Creating these categories and labeling them appropriately (i.e., group one, group two, etc.) allows students to be somewhat scaffolded from the content management system (CMS), with which they are often familiar, into the open practice environment. After adding students as users, a short video can assist them in creating posts and ensuring that they categorize their posts appropriately. In addition, Google folders may be created to as a tool for organized structure in course activities. Such folders can be open only to the course or to the public.

It is useful to allow beginners to "practice" a post and receive feedback before posting. It is recommended that beginners compose their posts in the CMS, receive feedback from their colleagues, and then make their postings in the classroom blog after any revision they feel necessary after reviewing the feedback. For instance, students may initially post to the CMS, give and receive feedback from their peers on the posting until a given day, and then post the next day to the open blog after making any revisions that they believe are important. This rehearsal of the post and trying it out on others can assist in building confidence. The rehearsal and final post cycle might continue for several weeks, until students are accustomed to displaying their work in an open environment.

It is important that beginners' posts are acknowledged with timely feedback by the instructor or peer. If an educator would like the classroom blog to include extended responses to the posts of others, he or she may choose to assign a group and require students to respond to their group members. Responses from others validate the beginner and document knowledge growth that continues through the course. 


\subsection{Open Practice with Designated Tools}

As students move into a more open practice in which they maintain and build their own social media presence, the open hub becomes more relevant in terms of acting like a portal to support learner connections to expanded learning environments, networks, and nodes of learning. For our courses, the open hub is a blog that the instructor creates for the class. It is a place at which students might start their interaction with classmates and then choose to branch off into designated social media aspects of information sharing and production. Use of this blog along with customized menus and easily configurable widgets provides students with a "home base" for a class offered in the open.

Knowledge generation in this configuration can occur in several ways. First, students may comment on any weekly assignment if they have questions or need guidance. This open posting allows immediate clarification of questions and information gain from others' posts, without leaving the assignment page. Secondly, the use of a Blogroll (a Google or other editable document on which students post the link to their blog) allows students to navigate to any user's blog from the hub page. There, we might extend that Google document by creating a navigation menu on the landing page of the blog, with student first names and links to their various blogs. We might also use the Wordpress Twitter widget to embed the instructor's username and display any new Tweets made by the instructor.

A common hashtag used in the title of student posts regardless of social media tool helps us to organize all hashtags through a Google search. This idea, made popular by massive open online courses such as \#moocmooc, \#change12, \#etmooc, and \#ds106 can assist students in finding posts from others to interact and using multiple social media tools in which they may creatively express their professional learning. Finding an unused hashtag could be difficult. It is important to use a hashtag that is easy to remember and unique to the class.

For instance, several years ago students participated in an open classroom environment for a University of Alaska Southeast graduate course in collaborative classroom research. The hashtag for the experience was \#seaccr. A search of this hashtag reveals student postings in Twitter, YouTube, and Wordpress among other social media tools. By using Paper.li (or an equivalent tool), students can set their preferences to receive a daily email that contains links to newly indexed social media posts that use this hashtag.

\subsection{Advanced Open Practice}

The community that may evolve in subsequent courses and builds on the open hub structure allows students to use social media tools of their choice. The use of these tools in concert with an open hub provides a level of organization that allows for organic growth in technological skill and open practice. The student who has been through the first and 
second stages of open practice may experiment using other tools more regularly, as choice is emphasized in assignments. Inviting more advanced students to use tools such as screencasting, podcasting, or other online multimodal learning tools to demonstrate their learning will assist them in exploring their preferences for knowledge generation. Also at this point, focusing on potential strategies or concepts can lead to student participation in unassigned Twitter chats and other informal learning communities. When students become familiar with archiving tools and accustomed to the hashtag and sharing, they grow easily into an extended and personalized form of knowledge generation.

\subsection{Assessing Student Work}

It is important throughout the model to remember that any comments pertaining to quality of a student post, alignment of the post with the standard, or numeric grade occur in the password-protected and private university grading hub. Instructors must avoid public criticism of student postings and keep a growth mindset (Dweck, 2008) as they gently encourage open knowledge generation to benefit both the student and others. Educators must be very conscious of the potential impact of this occurring in the open.

\subsection{Caveats}

Using an open hub as a pedagogical design approach for open-learning requires dedicated support from institutions, policy makers, and colleagues. An infrastructure must be in place to support open learning, including, for example, the institution hosting Wordpress blogs or alternative open source software. An institution's acceptable technology use policy must be flexible enough to support open technology tools, but firm enough to support securing student data and privacy.

Designing for an open hub is most successful when an instructor is able to collaborate with other like-minded instructors. As such, when instructors teach the same course with teachers, barriers and tensions may arise, especially if pedagogical perspectives are not aligned. Common assessment practices are also essential in that the assessment always connects to the course outcomes that include some kind of evidence of participatory learning. In addition, the learner experience is essential. Open hubs are different for undergraduate and graduate students of education because the relationship with instructors is different, and student confidence in their own learning and online learning experiences. All of these components influence the student's mindset when considering open learning.

\section{CONCLUSION}

When considering a pedagogical approach that encourages multiple learning pathways that expand in a plethora of directions and depends on stages of open readiness, a 
pragmatic networked pedagogical model is helpful. Open hub describes the process by which learner digital literacies, pedagogical mindset, and relationships (trust) grow by encouraging a participatory, active, and safe open-learning space. It is our belief that to engage in the open hub, instructors benefit from dynamically modeling work in the open. In addition, students must be treated as colearners rather than content deliverers in the experience. Participating in informal learning communities facilitates ongoing professional learning and allows students to create valuable digital footprints, forming an aspect of quality information that may be shared throughout their careers. Finally, students who engage in this structured but open environment access and incorporate resources for knowledge construction that become throughout their lives.

\section{REFERENCES}

Anderson, P.M. (2018), The Meaning of Pedagogy, in Kincheloe, J.L. and Steinberg, S.R., Eds., Classroom Teaching: 2nd Ed., New York: Peter Lang Publishing, pp. 17-28.

Brabazon, T. (2012), Wasted? Managing Decline and Marketing Difference in Third Tier Cities, J. Urban Regional Anal., 4(1), pp. 5-33.

Cormier, D. (2014), Rhizomatic Learning-The Community is the Curriculum, in P2PU, Retrieved from https://p2pu.org/en/courses/882/rhizomatic-learning-the-communityis-thecurriculum.

Cronin, C. (2017), Openness and Praxis: Exploring the Use of Open Educational Practices in Higher Education, Int. Rev. Res. Open Distance Learning, 18(5). DOI: 10.19173/ irrodl.v18i5.3096

Dewey, J. (2008), Democracy and Education: An Introduction to the Philosophy of Education, New York: Macmillan.

Downes, S. (2005), E-Learning 2.0, Retrieved from https://www.downes.ca/cgi-bin/page. cgi?post=31741.

Downes, S. (2012), Connectivism and Connective Knowledge: Essays on Meaning and Learning Networks, National Research Council of Canada, Retrieved from http://www.downes.ca/files/books/Connective_Knowledge-19May2012.pdf.

Drexler, W. (2014), Personal Learning Environments in K-12, in R. Ferdig and $\mathrm{K}$. Kennedy, Eds., Handbook of Research on K-12 Online and Blended Learning, Pittsburgh, PA: Carnegie Mellon University ETC Press, pp. 447-466.

Dweck, C.S. (2008), Mindset: The New Psychology of Success, New York: Random House Digital, Inc. 
Garrison, D.R., Anderson, T., and Archer, W. (2000), Critical Inquiry in a Text-Based Environment: Computer Conferencing in Higher Education, Internet Higher Ed., 2(2-3), pp. 1-19.

Graham, L. (2018), The Open Hub Model of Formal Knowledge Generation in Higher Education, Retrieved from https://wordpress.com/post/akedtech.wordpress.com/1266.

Graham, L. and Fredenberg, V. (2015), Impact of an Open Online Course on the Connectivist Behaviors of Alaska Teachers, Australasian J. Ed. Tech., 31(2), pp. 140-149.

Gros, B. and Maina, M. (2016), The Future of Ubiquitous Learning: Learning Designs for Emerging Pedagogies, London: Springer Publishing Company.

Guerin, C., Carter, S., and Aitchison, C. (2015), Blogging as Community of Practice: Lessons for Academic Development? Int. J. Acad. Dev., 20(3), pp. 212-223.

Hegarty, B. (2015), Attributes of Open Pedagogy: A Model for Using Open Educational Resources, Ed. Tech., 55(4), pp. 3-13.

Hinson, J., LaPrairie, K., and Heroman, D. (2006), A Failed Effort to Overcome Tech Barriers in a K-12 Setting: What Went Wrong and Why, Int. J. Tech. Teaching Learning, 2 (2), pp. 148-158.

Hodgkinson-Williams, C. and Gray, E. (2009), Degrees of Openness: The Emergence of OER at the University of Cape Town, Int. J. Ed. Development Using Information Comm. Tech., 5(5), pp. 101-116.

Howard, J. (2014), Service-Learning Research: Foundational Issues in Studying ServiceLearning, Abingdon, UK: Routledge, pp. 15-26.

Joksimovæ, S., Dowell, N., Skrypnyk, O., Kovanovæ, V., Gševæ, D., Dawson, S, and Graesser, A.C. (2015), How Do You Connect: Analysis of Social Capital Accumulation in Connectivist MOOCs, Proc. 5th Intl. Conf. Learning Anal. Knowledge, ACM, pp. 64-68.

Jones, A. and Graham, L. (2015), Democratizing Higher Education Learning: A Case Study of Networked Classroom Research, Int. HETL Rev., 5, pp. 1-18.

Koehler, M.J. and Mishra, P. (2009), What is Technological Pedagogical Content Knowledge?, Contemp. Issues Tech. Teacher Ed., 9(1), pp. 60-70.

Kral, I. and Schwab, R.G. (2012), Youth, Literacy and New Media in Remote Indigenous Australia, Canberra, Australia: ANU Press.

Lucier, R. (2017), Seven Degrees of Connectedness, Retrieved from https://ecoo.org/blog/ 2017/12/18/seven-degrees-of-connectedness/.

McCright, A. and Dunlap, R. (2017), Combating Misinformation Requires Recognizing Its Types and the Factors that Facilitate Its Spread and Resonance, J. Appl. Res. Mem. Cognit., 6(4), pp. 389-396. 
Miller, V. (2017), Phatic Culture and the Status Quo: Reconsidering the Purpose of Social Media Activism, Convergence, 23(3), pp. 251-269.

Mishra, P. and Koehler, M.J. (2008), Introducing Technological Pedagogical Content Knowledge, Annual Meeting of the American Educational Research Association, pp. 1-16.

O’Donnell, M. (2006), Blogging as Pedagogic Practice: Artefact and Ecology, Asia Pacific Media Ed., 17, pp. 5-19.

Richardson, J., Maeda, Y., Lv, J., and Caskurlu, S. (2017), Social Presence in Relation to Students' Satisfaction and Learning in the Online Environment: A Meta-Analysis, Comp. Human Beh., 71, pp. 402-417.

Roberts, V. (2018a), Building an Open Narrative with Open Learning. International Literacy Association, Retrieved from https://www.literacyworldwide.org/blog/literacy-daily/2018/ 08/31/building-an-open-narrative-with-open-learning.

Roberts, V. (2018b), Proposing OLDI (Version 1): An Open Learning Design Intervention for K-12 Open Educational Practice, Retrieved from http://www.openclassroomonline.com/ proposing-oldi-version-1-an-open-learning-design-intervention-for-k-12-open-educationalpractice/.

Siemens, G. (2004), Connectivism: A Learning Theory for the Digital Age, elearnspace, Retrieved from http://www.elearnspace.org/Articles/connectivism.htm.

Shulman, L. (1986), Those Who Understand: Knowledge Growth in Teaching, Ed. Res., 15 (2), pp. 4-31.

Powell, W. and Snellman, K. (2004), The Knowledge Economy, Ann. Rev. Sociolog., 30, pp. 199-220.

Thomas, D. and Brown, J. (2011), A New Culture of Learning: Cultivating the Imagination for a World of Constant Change, vol. 219, Lexington, KY: CreateSpace.

Wenger, E. and Lave, J. (2001), Legitimate Peripheral Participation in Communities of Practice, in Supporting Lifelong Learning, Abingdon, UK: Routledge, pp. 121-136.

White, D. and LeCornu, A. (2017), Visitors and Residents' to Visualise Digital Practices, First Monday, 22(8), Retrieved from http://firstmonday.org/ojs/index.php/fm/article/view/ $7802 / 6515$.

Wiggins, G. and McTighe, J. (2005), Understanding by Design, 2nd Ed., Alexandria, VA: Association for Supervision and Curriculum Development.

Wiley, D. and Hilton, J. (2018), Defining OER-Enabled Pedagogy, Int. Rev. Res. Open Distrib. Learning, 19(4). DOI: 10.19173/irrodl.v19i4.3601 
Wilson, S., Liber, O., Johnson, M., Beauvoir, P., Sharples, P., and Milligan, C. (2006), Personal Learning Environments: Challenging the Dominant Design of Educational Systems, J. e-Learning Knowl. Soc., 3(2), pp. 27-38. 